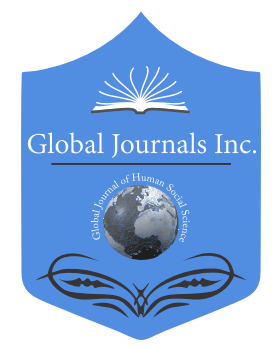

\title{
Social Support and Self-Esteem as Predictors of Psychological Distress among Students with Learning Disabilities in Accra, Ghana
}

By Clarice Jobson-Mitchual

Nottingham Trent University

Abstract- Using a survey research design, this study examined the extent to which social support and selfesteem predict psychological distress among students with learning disabilities at Multi Kids Inclusive Academy in Accra, Ghana. The Simple Random Sampling technique was used to select 94 students. Survey questionnaires containing the Child and Adolescent Social Support Scale (Malecki \& Demaray, 2002), Depression, Anxiety and Stress Scale (Lovibond \& Lovibond, 1995), and Adapted Rosenberg Self Esteem Scale (Dagnan \& Sandhu, 1999) were used to collected data. Descriptive statistics, Reliability and Normality tests, Simple Linear Regression Analysis, and the Pearson Product Moment Correlation Coefficient test within the Statistical Package for Social Sciences (SPSS) version 23 application software were used to analyze data. Results indicated that Social Support from Teachers $(\boldsymbol{\beta}=.202, p=.033)$ and Social Support from Classmates $(\boldsymbol{\beta}=.548, p=.000)$ predicts psychological distress. Social Support from Parents Dimension subscale $(\boldsymbol{\beta}=-.024, p=.810)$, did not predict psychological distress. In addition, a significant negative relationship was found between self- concept and psychological distress. Also, differences in gender $(\boldsymbol{\beta}=-.238, p=.033)$ and age $(\boldsymbol{\beta}=.266, p=.017)$ predicts psychological distress.

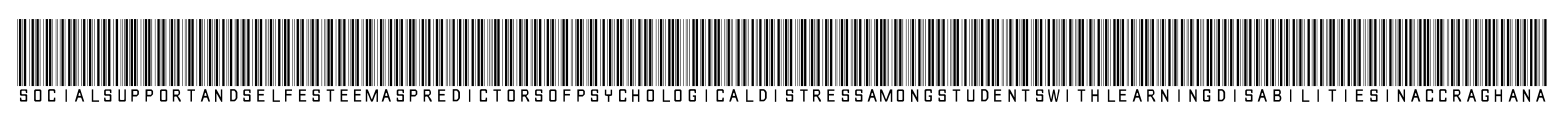

Strictly as per the compliance and regulations of:

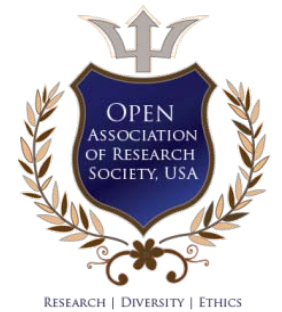

(C) 2021. Clarice Jobson-Mitchual. This is a research/review paper, distributed under the terms of the Creative Commons Attribution-Noncommercial 3.0 Unported License http://creativecommons.org/licenses/by-nc/3.0/), permitting all non-commercial use, distribution, and reproduction in any medium, provided the original work is properly cited. 


\title{
Social Support and Self-Esteem as Predictors of Psychological Distress among Students with Learning Disabilities in Accra, Ghana
}

\author{
Clarice Jobson-Mitchual
}

Abstract- Using a survey research design, this study examined the extent to which social support and self-esteem predict psychological distress among students with learning disabilities at Multi Kids Inclusive Academy in Accra, Ghana. The Simple Random Sampling technique was used to select 94 students. Survey questionnaires containing the Child and Adolescent Social Support Scale (Malecki \& Demaray, 2002), Depression, Anxiety and Stress Scale (Lovibond \& Lovibond, 1995), and Adapted Rosenberg Self Esteem Scale (Dagnan \& Sandhu, 1999) were used to collected data. Descriptive statistics, Reliability and Normality tests, Simple Linear Regression Analysis, and the Pearson Product Moment Correlation Coefficient test within the Statistical Package for Social Sciences (SPSS) version 23 application software were used to analyze data. Results indicated that Social Support from Teachers $(\boldsymbol{\beta}=.202, p=.033)$ and Social Support from Classmates $(\beta=.548, p=.000)$ predicts psychological distress. Social Support from Parents Dimension subscale $(\boldsymbol{\beta}=-.024, p=.810)$, did not predict psychological distress. In addition, a significant negative relationship was found between self- concept and psychological distress. Also, differences in gender $(\beta=-.238, p=.033)$ and age $(\beta=.266, p=.017)$ predicts psychological distress. It was concluded that, social support students with disabilities in learning receive from their teachers and classmates, and positive self-concept protect them against psychological distress (i.e. depression, anxiety and stress).

\section{INTRODUCTION}

G oing to school, studying, writing exams, among other activities captured under school-life is one of the most stress-inducing areas in the lives of young people (Khan, 2016). This is especially so among students with learning disabilities because their deficiencies make their teaching and learning more challenging (Wiesner-Groff, 2021), thus, this requires more psychosocial support (Cavioni, Grazzani \& Ornaghi, 2017). Most students with learning disabilities usually struggle with persistent episodes of frustration, anxiety, depression and are treated as second-class students (Cataudella, Carta, Mascia, Masala, Petretto \& Penna, 2021; Ehmke, 2021; Papanastasiou, 2017) in most parts of the world, especially in developing countries like Ghana. As a result, students with learning

Author: Ph.D candidate at Nottingham Trent University, M.Sc Applied Child Psychology (Nottingham Trent University, UK), M.Phil Guidance and Counseling (Methodist University College Ghana), Bachelor of Arts Psychology (Methodist University College Ghana).

e-mail: claricejobson@gmail.com disabilities usually struggle with negative self-concept, have little motivation to invest more effort in their academic work, thus, causing a decline in their academic performance (Sahoo, Biswas \& Padhy, 2015; Papanastasiou, 2017).

According to Jobson-Mitchual (2018) learning disability which are also known as learning disabilities are neurological in nature. They affect the processing of information, which in turn short-circuit fundamental learning abilities, and affect various subject areas like language, reading and mathematics. In addition, learning disability obstruct higher skills like time management, inability to concentrate, impaired reasoning, especially when attention is needed for a long time. The Diagnostic Statistical Manual IV (DSM-IV) of mental disorders defines learning disability as a condition in which individual's standard obtained in normal basic reading, math abilities, and written tests are below standard expected in relation to age, education, and reasoning level.

The most common forms of learning disabilities negatively affect writing, mathematical abilities and reading among students. These may be associated with other conditions like language problem, attention disorders, and behavior problems. However, they are all unique on how their impacts are felt on learning (Cataudella, et al., 2021). Examples of learning disabilities include dyslexia, dyscalculia, dysgraphia, dyspraxia, auditory processing disorder and dyspraxia. Dyslexia is a specific learning disability that disturbs reading and associated processing skills that depend on language. Even though its symptoms sometimes differ from individual to individual, it negatively affects the students' ability to read smoothly, write, spell words and remember things that has been learnt. Meanwhile, Dyscalculia is a learning disorder that renders people incapable of understanding and recalling anything related to numbers and mathematics (symbols, formulas, etc.). On the other hand, Dysgraphia is characterized by poor fine-coordination abilities and are unable to write. Also, students with Auditory Processing disorder (central auditory processing disorder) are unable to recognize the slight differences of sounds in words even in cases where the sounds come out very loud and clear enough to hear. These students are unable to tell the direction where sound is coming from. 
In rare instances they can tell the direction a sound is coming from with extreme difficulty, coupled with difficulty in filtering out confounding noise. Finally, Dyspraxia is associated with the struggle to control muscle, thereby making it difficult to move and bring the muscles under control. This causes problems in coordination, speech, language and can impede learning. This condition is often with dyslexia, dyscalculia, or attention deficit and hyperactive disorder (ADHD) (Jobson-Mitchual, 2018; Sahoo, Biswas \& Padhy, 2015). Avoke and Yekple (2006) have reported learning disabilities as the most prevalent type of school related problem among other difficulties (i.e. hearing impairments, visual impairments) in most schools in Ghana. It therefore seems odd that little effort has been made to study this area research-wise (Attah, 2012).

According to Walsh (2018), learning disability is the most commonly diagnosed disability that has the most negative impact on children, adolescents, schools and society at large. In fact, in the largest group of special needs students are those with learning disabilities in North America (Shukla \& Agrawal, 2015; Whitley, 2008). Learning disabilities has a negative effect on students-teacher relationships when unnoticed or when overlooked. Also, hardly are normal schools able to meet the requirements of children with learning disabilities in terms of meeting their unique academic needs (Shukla \& Agrawal, 2015).

Students with learning disabilities are required go beyond the usual classroom work and do extra work compared with their counterparts who do not have learning disabilities, so as to maintain their grades with their equals (Jobson-Mitchual, 2018). As a result of this, most of them struggle with psychological distress, and require extra guidance and direction to enable them to accomplish a task successfully within a given frame of time in and outside of the classroom. This, however, does not mean lack of intelligence, but they possess a different learning method (Jobson-Mitchual, 2018). Nevertheless, most students with learning disabilities perform poorly in their academic work when compared to their non-learning disabled counterparts (Flisher, Malhotra, Nikapota \& Patel, 2008; Sahoo, Biswas \& Padhy, 2015; Walsh, 2018).

Over the years, various researchers have spent substantive amount of time, among other resources studying the antecedents and implications of learning disabilities. Some studies conducted in this research area have discovered that, the level of social support offered to children with learning disabilities has a direct effect on their mental well-being. In other words, children who receive higher social support from significant others (e.g. family, friends and peers) are more likely to experience less psychological distress, when compared to those who receive little or no social support from significant others (Barth, Schneider, \& von Känel, 2010; Pinquart \& Duberstein, 2010; Waters, Lester \& Cross,
2013; Zhang et al., 2014). Hence, social support serves as a buffer against psychological distress (e.g. stress, anxiety and depression) and psychological disorders (e.g. post-traumatic stress disorder, etc.) (Gerich, 2013; Ozbay et al., 2007). Similar to their other counterparts, most children with learning disabilities easily perceive negative behaviours towards them, and when this persists it undermines their ability to adaptively cope with their disability (Rothman \& Cosden, 1995). Yet, when people around them (especially their parents) offer them the needed social support it helps protect them from being psychologically distressed (Fiorillo \& Sabatini, 2011; Hapke, 2015; Waters, Lester \& Cross 2013; Zhang et al., 2014).

Social support as defined by Cukor and Kimmel (2017) is the extent to which one experiences a sense of belongingness within a society where one can provide and receive affection, from family, peers, and other members of the society. Scott (2020) has classified social support into four main types: emotional social support, informational social support, esteem social support and tangible social support. Tangible social support is offered when an individual is supported with assistance (e.g. given money, food, etc.) to help them manage a problem. Meanwhile, esteem social support is offered when people express their confidence and encouragement to a child with the aim of boosting their self-esteem (i.e. belief in themselves). On the other hand, informational social support has to do with giving a someone guidance, suggestion, useful information or an advice. Finally, emotional social support often involves physical comfort such as hugs or pats on the back, as well as listening to and empathizing with others (Scott, 2020).

The self-concept of student has also been found to be influenced by students' intellectual aptitude. Specifically, students with learning disabilities have been found to have lower self-concept, when compared to their counterparts who have higher intellectual aptitude (Lindeblad, Nilsson, Gustafson \& Svensson, 2019; McKenzie, Murray \& Derries, 2020). According to Baumeister (1999) self-concept is the manner in which an individual evaluates the awareness he or she has about himself/herself including his attitudes. Selfconcept is also related to how an individual rates his worth which may include a general view of their social acceptance and their personal feelings about who they are (Bellmore \& Cillessen, 2006). According to Sternke (2010) peoples' self-concept, usually develops based on their experiences and how those experiences are evaluated. The self-concept of younger people is easily changed because their life is driven by self-discovery. The direct opposite applies to older people because their self-concept is more resolute and organized because their conception about who they are set (Cherry, 2017). 
Most empirical studies conducted in this research area were conducted outside Africa and in developed countries (Ramaa, 2000). In the face of this low level of knowledge about this subject, the emphases have rather been on intervention measures by researchers in Africa without going deep to have a look at the situation as it manifests in African children (Jobson-Mitchual, 2018). In addition, even though researchers have conducted some studies among students with learning disabilities, studies in this research area is far from being conclusive, especially in the area of the psychological experiences of students with learning disabilities (Walsh, 2018). It is, therefore, imperative to examine the extent to which social support and self-concept predict psychological distress among students with learning disabilities at the Multi kids Inclusive Academy in Accra, Ghana.

\section{a) Objectives of the Study}

The general objective of the study is to investigate the effect of social support (from parents, teachers and classmates/peers) and self-concept on psychological distress. The specific objectives of the study were:

i. To examine the relationship between social support and psychological distress among students with learning disabilities.

ii. To find out the nature of relationship that exist between self-esteem and psychological distress among students with learning disabilities.

iii. To ascertain whether differences in gender and age predict psychological distress among students with learning disabilities.

\section{b) Statement of Hypothesis}

i. There will be a negative correlation between social support and psychological distress among students with learning disabilities.

ii. A significant negative relationship will exist between self-esteem and psychological distress among students with learning disabilities.

iii. Differences in gender and age will predict psychological distress among students with learning disabilities.

\section{il. Literature Review}

a) Correlation between social support and psychological distress

Studies such as that of Hapke (2005) and Bane, Deely, Donohoe, Dooher and Flaherty (2012) have revealed that having the needed social support among students with learning disabilities goes a long way to help them cope with their condition. Specifically, it was discovered that students with learning disabilities gain a lot from a robust social support network system from parents, siblings, teachers and schoolmates (Hakpe, 2016). Nevertheless, Heiman's (2006) study which targeted 191 students with learning disability and 190 students without learning disability discovered that, students with learning disabilities saw themselves as not having much support compared with their nonhandicapped counterparts. Heiman's (2006) result reinforced that of Pavri and Monda-Amaya (2001) who discovered that even though students with learning disability usually feel lonely especially when they are in school. As a result of this, students with learning disabilities actively seek social support from significant others like parents, siblings, among others (Bane et al., 2012).

One of the reasons why looking into the level of social support sought and received by students with learning disability is important, is because social support correlates with their psychological well-being (Fauziah \& Muslihati, 2018). In other words, social support (from family members, peers, teachers, and coaches) leads to lower psychological distress and vice versa (Hapke, 2015). Given its benefits to people's mental health, a strong and reliable social support network may be particularly critical during adolescence because it is one of the most critical developmental stages in life (Hapke, 2015). This is because adolescents usually, experience rapid biological, social, emotional and cognitive changes that redefines the ways they engage with family members, peers, friends, and teachers (del Valle, Bravo, \& Lopez, 2010; Martínez, Aricak, Graves, Peters-Myszak, \& Nellis, 2011). In their research, Zhang et al. (2014) discovered that students between the ages of 13 to 16 experience psychological distress (stress and depression), and this is intense among those who have little or no social support from their peers. Zhang et al.'s (2014) result reinforced that of del Valle et al.'s (2010) finding indicated that social support among young students with learning disabilities helps in protecting them against psychological distress. In addition, these students usually depend on their peers for emotional support, and their parents for advice, assistance, and support (del Valle et al., 2010).

Similarly, Waters, Lester and Cross (2013) found that support from parents has the most significant effect on how students will cope with psychological distress. Thus, among the various sources of social support, social support received from parents has the most significant effect against psychological distress. Meanwhile, Barrett's (2012) results showed that female teenagers with learning disabilities record higher degrees of distress than their male counterparts. Adolescents who were high on how they anticipate tangible social support emotional support reported low degrees of distress (Barrette, 2012).

Nevertheless, in their research Jeena and Aswathi's (2004) result indicated that students with learning disabilities also face strained family relationship which leads to lower social support, thus, undermining their psychological wellbeing. Wendelborg, and Kvello 
(2010) further found that children with disabilities often have a harder time creating strong relationships with peers, and usually face more barriers when trying to participate in extra curricula activities. As a result of this, students with learning disabilities receive less social support from significant others, thus, making them more susceptible to psychological distress (Coster et al., 2012; Wendelborg \& Kvello, 2010).

\section{b) Relationship between self-concept and psychological distress}

Over the years, studies conducted among young people have revealed that there exist high levels of psychological problems among students with learning disabilities (Carroll, Maughan, Goodman, \& Meltzer, 2005; Maughan \& Carroll, 2006). Specifically, meta-analyses of various studies done in this research area has shown that the level of depression (Maag \& Reid, 2006; Nelson \& Harwood, 2011) and anxiety (Nelson \& Harwood, 2011) is high among students with learning disabilities.

Further, studies; Lahane, Shah, Nagarale and Kamath (2013), Leminen (2002), Gans, Kenny and Ghany (2003), Zeleke (2007), Zigmond (1993), among others have discovered that the self-concept of students with learning disabilities is lower than students without learning disabilities. Nevertheless, the implication of this result could be well appreciated when follow-up studies such as Walsh (2018). Specifically, in his Canadian study Walsh (2018) discovered that negative selfconcept among students with learning disability makes them susceptible to high psychological distress. Walsh's (2018) findings reinforced that of Fauziah and Muslihati (2018) whose result indicated that, there exist a significant negative relationship between self-concept and psychological distress among students with learning disabilities. Thus, positive self-concept reduces psychological distress among students with learning disabilities (Fauziah \& Muslihati, 2018).

Similarly, Tam and Hawkins (2012) examined the effect of self-concept and psychological distress (i.e. level of depression) among students diagnosed with dyslexia in Singapore. A sample size of 30 students between the ages of 8 to 13 years were used. After data analysis, result revealed that a rise in self-concept reduces symptoms of psychological distress (Tam \& Hawkins, 2012). Tiga and Vashishtha's (2010) study also discovered that that self-concept predicts anxiety levels of students with learning disability. Similarly, Alesi, Rappo and Pepi (2014) discovered the existence of high levels of depression and school anxiety among students with learning disabilities who had negative self-concept. It could therefore be concluded that students who have negative self-concept are susceptible to developing psychological distress (Alesi, et al., 2014; JobsonMitchual, 2018; Tam \& Hawkins, 2012; Tiga \& Vashishtha, 2010).
From the above it could be concluded that even though some studies have been conducted in this research area, they were relatively few. In addition, most studies captured in this review were conducted outside Ghana and Africa. And considering the fact that sociocultural environmental factors sometimes have an effect on most behavioural outcomes, it is an undeniable fact that a research gap exists, for which reason this present study hopes to address.

\section{ili. Methods}

\section{a) Research Design}

The research design used in this study was a survey. Survey research design is generally versatile because it could be adjusted to suite challenging situations, and it is also suitable for quantitative studies (Creswell, 2014). The reason why a survey is the most appropriate research design was the fact that the goal of this present research and quantitative research, in general, is to generalize findings to the entire population target for this study.

\section{b) Study Population}

The target population for the study were students of Multi kids Inclusive Academy located in Accra, Ghana. Multi kids Inclusive Academy is a special school for students with various physical, developmental, and intellectual impairments. Out of these students, those with learning disabilities formed the population for this study.

\section{c) Sampling Technique and Sample Size}

The simple random sampling technique was used to select 94 students with learning disabilities. Respondents had a variety of mild to moderate learning disabilities, including dyslexia, dyscalculia, dysgraphia and ADHD. Inclusion Criteria: Respondents used in this study met the following: Firstly, they were between the ages of 10 to 18 years. Secondly, respondents were assessed and diagnosed by a professional as having a learning incapacity. Finally, respondents enrolled in the targeted school because their disability is identified chiefly at a school-going age.

\section{d) Data Collection Too/s}

Questionnaires were used to collect data from respondents. The questionnaire was subdivided into three sections: Section A, B and C. Section A of the questionnaire focused on respondents' gender, age and class/form.

Sections B of the questionnaire contained the Child and Adolescent Social Support Scale (CASSS; Malecki \& Demaray, 2002). The child and adolescent social support scale (CASSS) is a 60 -item self-report assessment scale that measures observed social support for children in grades 3 through 12. The CASS consists of 5 subscales which focuses on five (5) potential sources of social support: Parents, Teachers 
and Classmates and Close Friend. The items of the scale were reduced to 36 , and were divided into three subscales: Social Support from Parents, Social Support from Teachers and Social Support from Classmates/ friends. Items in the CASSS include "My teacher helps me solve problems" and "My parents show they are proud of me." The scale is scored on a 6-point Likert scale which ranges from $1=$ Never, $2=$ Almost Never, 3 = Some of the Time, $4=$ Most of the Time, $5=$ Almost Always to $6=$ Always. These three subscales scores can then be added to result in a general summed up social support score. In like manner, importance ratings are added together for all subscales and then the three subscale scores are added together for generate scores for overall social support. Psychometric properties of the measure have been thoroughly evaluated, demonstrating reliability with overall robust internal consistency of $\alpha=0.96$, and subscales internal consistency of $\alpha=0.93-0.96$. The reliability of test-retest is between 0.75 to 0.78 , for total frequency scale. The validity of CASSS has significant associations with a correlation coefficient of 0.70 with the social support scale for children (Harter, 1985; Malecki \& Demaray, 2002).

Section C of the questionnaire contained 21item Depression, Anxiety and Stress Scale (DASS-21). The DASS-21 has 3-subscales: Depression, Anxiety, and Stress. The combination of the three subscales makes it a Psychological Distress scale. In other words, psychological distress as indicated in this scale is the combined score for three psychological health conditions; depression, anxiety and stress in the past week. Items in the DASS include "I found it hard to wind down", "I tended to overreact to situations" and "I felt scared". Items are scored on a 4-point scale: $0=$ "Did not apply to me at all", 1 = "Some of the time (Applied to me to some degree)", 2 = "A good part of the time (Applied to me a considerable degree)", and $3=$ "Most of the time (Applied to me very much)." Total scores were generated by summing up all the scores on the items on subscale basis and multiplied by a factor 2 . The DASS-21 has a Cronbach's alpha of DASS-D = 0.94 , DASS-A $=0.87$, and DASS-S $=0.91$.

The Section $D$ of the questionnaire contained the Adapted Rosenberg Self Esteem Scale (Dagnan \& Sandhu, 1999). The scale is one of the most popular measures for self-esteem (Rosenberg et al., 1989). This scale was later modified to be used for individuals suffering mental incapacities and their self-esteem using 6-items (Dagnan \& Sandhu, 1999). The RSES has an internal reliability and structure that fits what Rosenberg anticipated in his self-esteem theoretical model. Items in this scale included "I like myself", "I feel that I have a lot of good qualities", etc. The scale is made up of two positive and negative worded items (Dagnan \& Sandhu, 1999). Items that had negative structures were reversed scored. The respondents will be asked to respond how they rate how much they are in favor of the items on a five point Likert scale: $1=$ Never true, $2=$ Hardly ever true, 3 = Sometimes True, $4=$ Often True, and 5 = Almost True. Responses are scored between the range 1 to 5 for each item, and the overall score is generated by adding the scores of all items. A higher score indicated high self-esteem, whereas a lower score indicates lower self-esteem. The RSES has a Cronbach's alpha of 0.66 .

\section{e) Data Collection Procedure}

The researcher used the help of some teachers and teaching assistants at the Multi kids Inclusive Academy in Accra, Ghana. During data collection, the research team presented the students with some knowledge concerning the research goals and provided clear instructions for each part of the questionnaires. Instructions were repeated to help students understand better because participants have been diagnosed with mild to moderate learning disabilities. Questions asked by curious respondents were all answered before and during the study. Ghanaian local dialect Twi, and English language were used to explain questions to respondents. The participants were assured that the test was not part of the school curriculum and would not affect their school results. The participants were made to understand that all answers were neither right nor wrong, and they were to take control of what they were responding to. Members of the research team assisted most respondents in completing their questionnaires. Out of 110 questionnaires that were given to respondents to complete, 94 completed and submitted. Respondents were engaged in small groups of 20 students, and data collection was completed within four weeks.

\section{f) Data Analysis and Presentation}

Statistical tests within the Statistical Package for Social Sciences (SPSS) version 23 application software was used to analyze data. Specifically, Descriptive statistical tests, Reliability and Normality tests, Simple Linear Regression tests, and the Pearson Product Moment Correlation Coefficient test were used. Thereafter, appropriate APA tables were used to present results, followed by their interpretations.

\section{g) Ethical Consideration}

Institutional Approval was sought by acquiring an introductory letter from Methodist University College Ghana's Psychology Department. This letter was submitted to the Principal of Multi kids Inclusive Academy to seek permission to collect data from their students.

After permission was granted, students were asked to send a consent form to their parents or guardians. Guardians were required to append signatures to a consent form that students were asked to take home and return to school after obtaining 
signatures of parents and giving permission for their ward to take part in the study.

Participants were assured of confidentiality and were given the opportunity that at any time they could withdraw from the study. Also parents and guardians were also given the chance to withdraw their children from participating. Consent to participate was high across both schools. Selected individuals who were not given approval to participate in the study were replaced.

Participants were not forced to partake in the study but did so voluntarily. They were given the right to withdraw from the study at any stage if they wish to. The research was friendly and caused no form of harm to the participants in any way. The dignity of the participants was prioritized. Data obtained from the study was kept under lock and key. Anonymity of their responses was also assured with further emphasis on the fact that the study was purely being used for academic purposes. The code of ethics as prescribed by the American Psychological Association was also strictly followed.

\section{Results}

\section{a) Sample Characteristics}

The background information (i.e. gender, age and grade) of respondents, who are made up of 94 students with different forms of learning disabilities at the Multi Kids Inclusive Academy in Accra, Ghana, are presented in below in Table 2:

Table 2: Descriptive Statistics on Respondents' Gender, Age and Grade.

\begin{tabular}{|l|c|c|}
\hline \multicolumn{1}{|c|}{ Groups } & Frequency (N) & Percent (\%) \\
\hline Gender & & \\
\hline Male & 27 & 28.7 \\
\hline Female & 67 & 71.3 \\
\hline Age & & \\
\hline 10-14years & 85 & 90.4 \\
\hline 15-18years & 9 & 9.6 \\
\hline Grade & & \\
\hline Form one & 89 & 94.7 \\
\hline Form three & 5 & 5.3 \\
\hline Total & 94 & 100 \\
\hline
\end{tabular}

Table 2 shows that 127 respondents used in this study, out of this number $28.7 \%$ were males and $71.3 \%$ were females. In addition, $90.4 \%$ of respondents were between ages 10 to 14 years whiles $9.6 \%$ were between the ages of 15 and 18years. Finally, $94.7 \%$ of respondents were in Form one whiles the remaining $5.3 \%$ were Form two students. This therefore shows that most students with learning disabilities used in this study were female Form one students who are between the ages 10 to 14 years.

\section{b) Preliminary Analysis}

The preliminary analysis of this study presents result on the descriptive statistics and normality of data (i.e. skewness, kurtosis), as well as the correlation between variables. The goal is to ascertain the extent to which data can be used for regression analysis.

Table 3: Descriptive Statistics on Variables

\begin{tabular}{|l|c|c|c|c|c|}
\hline \multicolumn{1}{|c|}{ Variables } & M & SD & Skewness & Kurtosis & $\boldsymbol{\alpha}$ \\
\hline Social Support & 138.94 & 12.70 & -.24 & -1.09 & .68 \\
\hline Social Support from Parents & 52.60 & 5.61 & .24 & -.74 & .62 \\
\hline Social Support from Teachers & 44.53 & 7.14 & -.20 & -1.16 & .70 \\
\hline Social Support from Classmates & 41.21 & 9.21 & -.53 & -1.25 & .76 \\
\hline Psychological Distress & 20.49 & 12.23 & -.07 & -1.31 & .90 \\
\hline Depression & 6.26 & 3.78 & .07 & -.91 & .84 \\
\hline Anxiety & 8.26 & 5.63 & -.09 & -1.19 & .85 \\
\hline Stress & 5.98 & 4.08 & .42 & -.63 & .64 \\
\hline Self-Concept & 18.78 & 4.96 & .52 & -.65 & .82 \\
\hline
\end{tabular}


Table 3 presents results on the mean scores (M) together with their corresponding standard deviations (SD) on the variables [i.e. social support (with its subscales), psychological distress (with its subscales) and self-concept] used in this study. Observation of the result in the table indicates that all the variables fell within the required range of normality measured in terms of skewness and kurtosis. According to Tabachnick and Fidell (2013) normality is accepted when it falls within -1 and +1 . Hence all variables were normally distributed. In addition, Cronbach alphas $(\alpha)$ which represented the coefficient of internal consistency have also been presented. Measures generally had satisfactory reliabilities, with alpha values ranging from .68 to .90 for the overall scales, and .62 to .85 for the subscales. Coefficient alpha that is higher than or equal to .70 is reliable (Nunnally, 1978). This therefore indicates that variables can be used in a regression analysis.

Table 4: Inter Correlation Matrix on Variables

\begin{tabular}{|c|c|c|c|c|c|c|c|c|c|}
\hline Variables & 1 & 2 & 3 & 4 & 5 & 6 & 7 & 8 & 9 \\
\hline 1. Social Support & -- & & & & & & & & \\
\hline 2. Social Support from Parents & $.656^{\star \star}$ & -- & & & & & & & \\
\hline 3. Social Support from Teachers & $441^{* *}$ & -.036 & -- & & & & & & \\
\hline 4. Social Support from Classmates & $.740^{\star *}$ & $.363^{* *}$ & $-.324^{* *}$ & -- & & & & & \\
\hline 5. Psychological Distress & $.479^{* *}$ & .168 & $.293^{\star *}$ & .171 & -- & & & & \\
\hline 6. Depression & $.689^{* \star}$ & .213 & $.309^{\star \star}$ & $.470^{\star *}$ & $.873^{\star \star}$ & -- & & & \\
\hline 7. Anxiety & $.362^{* \star}$ & 182 & $.233^{*}$ & .117 & $.945^{\star \star}$ & $.749^{* \star}$ & -- & & \\
\hline 8. Stress & $.271^{*}$ & .033 & $.271^{\star \star}$ & -.084 & $.887^{\star \star}$ & $.659^{* *}$ & $.761^{* *}$ & -- & \\
\hline 9. Self-Concept & 153 & $291^{* *}$ & $-.353^{\star *}$ & $.381^{* *}$ & $-.204^{*}$ & .093 & $-.231^{*}$ & $-.380^{\star *}$ & -- \\
\hline
\end{tabular}

*. Correlation is significant at the 0.05 level (2-tailed).

**. Correlation is significant at the 0.01 level (2-tailed).

The inter correlation matrix as indicated in Table 4 shows that Social support with its subscales (social support from parents, social support from teachers, and social support from classmates) correlate with Psychological Distress with its subscales (depression,

anxiety and stress) and Self-concept. This, therefore, shows that there is a correlation between variables used in this study. Hence, they can be used in a regression analysis.

\section{c) Results for Tested Hypotheses}

Hypothesis One: There will be a negative correlation between social support and psychological distress among students with learning disabilities. Result is presented in Table 5:

Table 5: Simple Linear Regression Test Result on the extent to which Social Support Predict Psychological Distress.

\begin{tabular}{|c|c|c|c|c|}
\hline Predictors (subscales) & $\boldsymbol{\beta}$ & $\mathrm{R}$ & $\mathrm{R}^{2}$ & $\mathbf{p}$ \\
\hline Social Support from Parents & -.024 & & & .810 \\
\hline Social Support from Teachers & .202 & & & .033 \\
\hline Social Support from Classmates & .548 & & & .000 \\
\hline Total & & .554 & .307 & \\
\hline
\end{tabular}

The Simple Linear Regression Analysis result presented in Table 5 shows that social support explains approximately $31 \%$ of variance $\left(R^{2}=.307, F(3,81)=\right.$ $11.948, p=.000)$ in psychological distress among students with learning disabilities. The Social Support from Teachers dimension subscale $(\beta=.202, p=.033)$ and Social Support from Classmates dimensions $(\beta=.548, p=.000)$ predicts psychological distress. Meanwhile, Social Support from Parents Dimension subscale $(\beta=-.024, p=.810)$, did not predict psychological distress. This implies that the social support students with disabilities in learning receive from their teachers and classmates protects them from psychological distress (i.e. depression, anxiety and stress). Hypothesis one is partially accepted. 
Hypothesis Two: A significant negative relationship will exist between self-esteem and psychological distress among students with learning disabilities. Result is presented in Table 6:

Table 6: Pearson Product Moment Correlation Test Result on the Relationship between Self-Concept and Psychological Distress.

\begin{tabular}{|c|c|c|c|c|}
\hline Variables & M & SD & $r$ & $p$ \\
\hline Self-Concept & 18.78 & 5.96 & & \\
\hline Psychological Distress & 20.49 & 12.23 & & \\
\hline Total & & & $-.204^{*}$ & .049 \\
\hline
\end{tabular}

As shown in Table 6, the Pearson Product Moment Correlation Coefficient test was used to determine whether a significant negative relationship exist between self-concept and psychological distress in students with learning disabilities. Result $(r=-.204, p=$ 049) showed that a significant negative relationship exists between self-esteem and psychological distress among students with learning disabilities. This implies that a positive self- concept reduces students' level of psychological distress (i.e. stress, anxiety and depression). Hypothesis two is accepted.

Hypothesis Three: Differences in gender and age will predict psychological distress among students with learning disabilities. Result is presented in Table 7:

Table 7: Simple Linear Regression Test Result on the extent to which Gender, Age and Grade Predict Psychological Distress.

\begin{tabular}{|c|c|c|c|c|}
\hline Predictors & $\boldsymbol{\beta}$ & $\mathbf{R}$ & $\mathbf{R}^{2}$ & $\mathbf{p}$ \\
\hline Gender & .238 & & & .033 \\
\hline Age & .266 & & & .017 \\
\hline Total & & .439 & .192 & \\
\hline
\end{tabular}

Analysis result presented in Table 7 shows that differences in the Age and Gender explains approximately $19 \%$ of variance $\left(R^{2}=.192, F(2,91)=\right.$ 10.834, $\mathrm{p}=.000$ ) in psychological distress among students with learning disabilities. Specifically, gender $(\beta=-.238, p=.033)$ and age $(\beta=.266, p=.017)$ predicts psychological distress. This implies that differences in gender (i.e. being male or female) and age of students with disabilities in learning disabilities influences their levels of psychological distress (i.e. depression, anxiety and stress). Hypothesis three is accepted.

\section{Discussion}

Result for the first hypothesis indicated that social support explains approximately $31 \%$ of variance in psychological distress among students with learning disabilities. Specifically, social support from teacher and social support from classmates were found to predict psychological distress. This implies that the social support students with disabilities in learning receive from their teachers and classmates protects them from psychological distress (i.e. depression, anxiety and stress).

The result for the first hypothesis is not surprising because the education system in Ghana and most of the world is designed in such a way that most student spend their day in school engaged in curricula and extra curricula activities. As a result of this students with disabilities spend most of their time with their teachers and classmates (peers). This trend has made the influence of their teachers and classmates on their psychosocial development stronger than that of their parents. As such students seek and receive more social support from their teachers and classmates than their parents.

In addition, Accra, just as most modern cities in the world prides itself in its infrastructural development and rising population of middle income families. Yet, the down sides in living in a fast growing urban city is the fact that most parents tend to spend more time outside the home either working or commuting from home to the workplace or from the workplace to the house. As a result of this, even though, their children spend most of their time in school, they hardly get to spend quality time with their children at home. Interestingly, some parents compensate their absence at home by buying their children whatever they want, or pay someone to help their children with their homework. So when children are psychologically distressed (that is experience stress, anxiety or depression) they usually get seek and receive social support from their classmates and teachers. This social support serves as a buffer against psychological distress when compared to the social support they receive from their parents. Hence, the reason why social 
support received from teachers and classmates help protect students from psychological distress than social support received from parents.

Some theories such as the attachment theory propounded by John Bowlby and Mary Ainsworth even argue that the persistent neglect of children's biopsychosocial (biological, psychological and social) needs especially in critical stages in their lives (i.e. from birth to 4 years, and from 10 to 18 years) increases their susceptibility to develop maladaptive psychological conditions such as cognitive disorders (e.g., learning disorders), psychological distress (e.g. stress, anxiety, depression, etc.), personality disorders, among others. Hence, even though classmates and teachers are able to provide social support for children, has children received more social support from their parents, it would have had a more lasting effect on children. This is because as children progress in their schooling, they tend to change teachers and classmates. So if they overly rely on specific teachers or classmates for social support, and it is unavailable at some stage in their lives, the disruption may have an indirect effect on their psychological wellbeing. This is especially so among students with learning disabilities due to their fragile psychological health.

The findings for the first hypothesis is supported by that of Pinquart and Duberstein (2010), Waters, et al. (2013) and Zhang et al. (2014) which revealed that social support received by students with learning disabilities has a direct effect on their psychological well-being. Specifically, when students with learning disabilities receive the needed (tangible, emotional, esteem and informational) social support from significant others (i.e. parents, siblings, peers, etc.) it will help protect them against psychological distress. Pinquart and Duberstein (2010), Waters, et al. (2013) and Zhang et al. (2014)'s argument is supported by that of Fiorillo and Sabatini (2011) and Hapke (2015). Specifically, Fiorillo and Sabatini (2011) and Hapke (2015) findings revealed that social support received by children with learning disabilities reduces their propensity of being psychologically distressed.

The weakness in the above studies conducted by Pinquart and Duberstein (2010), Waters, et al. (2013) and Zhang et al. (2014) is their failure to ascertain the specific sources of social support (i.e. parents, siblings, peers, etc.) that mitigate against psychological distress among children with learning disabilities. They also, failed to espouse the effect of various types of social support (i.e. tangible, emotional, esteem and informational social support) and individually affect students with leaning disability's mental health. This weakness has been addressed in this present study's findings; this present study focused on how various sources of social support (teachers, classmates and parents) predicted psychological distress among students with learning disabilities.
Result for the second hypothesis indicated the existence of a significant negative relationship between self-concept and psychological distress among students with learning disabilities. This implies that a positive a students' self-concept reduces level of psychological distress (i.e. stress, anxiety and depression). Thus, when an individual with learning disability's self-concept becomes more positive, it leads to a reduction in his or her levels of psychological distress.

This result could be explained using Baumeister (1999)'s explanation for self-concept which focuses on an individual's mindset about themselves including their attitudes. In other words, when a student with learning disability has a negative self-concept (e.g., sees himself as mentally unstable) his or her negative self-concept could influence him or her to give into anxiety, stress or depression. This is so because people with lower selfconcept have been found to be more susceptible to developing psychological problems, whereas, people with a positive self-concept have more resilient against psychological problems. Hence, the more positive one's self-concept it the less likely are they to be psychologically distressed.

Nevertheless, according to Jobson-Mitchual (2018) even though students with learning disabilities are said to have negative self-concept, relatively little literature is available about the degree to which negative self-concept impacts mental health of children. In the United States, around $70 \%$ of students with some form of learning disorder also suffer from low self-concept (Kavale \& Forness, 2003).

According to Tam and Hawkins (2012) children learning disability do also suffer from negative selfconcept but also have other psychological conditions such as psychological distress. The reason why most children with learning disabilities also suffer from negative self-concept is because they have the tendency of being branded as lazy, they frequently experience rejection, and teasing, humiliated, among other negative treatments not only from strangers but those who are close such as siblings and even some parents (Tam \& Hawkins, 2012). This, therefore, makes them more inclined to be depressed, rejection sensitive, anxious and stressed.

One other factor that increases the levels of psychological distress among students with learning disorders is the fact that they perform poorly at school and other learning setting, and also perform poorly at some social skills (Kavale \& Forness, 1996). As a result of their academic struggles and low performance most students with learning disabilities also experience disapproval from their parents, school teachers and classmates (Kavale \& Forness, 1996).

All these lead children to develop a dilemma of frustration and shame instead of a sense of pride and positivity. A negative self-image may develop as a result 
of constant struggle and failure (Kavale \& Forness, 1996). Declined self-esteem and nonexistence of selfassurance usually lead to further decline in learning and educational success and strengthen a cycle of disappointment and negativity (Kavale \& Forness, 1996). As a result of this, research articles such as that of Svetaz, et al. (2000) are of the view that students with learning disabilities are more prone to developing psychological problems when compared compared to their non-learning disabled counterparts. Svetaz, et al. (2000) further stated that the source of several society's negative interpretation of people having learning disabilities stems from the use of tags for learning incapacity as verbal abuse.

Tam and Hawkins (2012), Puspalata, (2008), and Tiga and Vashishtha (2010) reinforced the above study by stating that as per their findings, self-concept leads to a reduction in the psychological distress levels among children having learning disabilities. We can imply therefore that a significant negative relationship indeed exists between self-concept and psychological distress among students with learning disabilities.

The third result indicated that differences in the Age and Gender explains approximately 19\% of variance in psychological distress among students with learning disabilities. Specifically, gender and age predicts psychological distress. This implies that differences in gender (i.e. being male or female) and age of students with disabilities in learning disabilities influences their levels of psychological distress (i.e. depression, anxiety and stress).

The result for the third hypothesis reinforced that of Deasy, Coughlan, Pironom, Jourdan and MannixMcNamara (2014) whose findings indicated that differences in respondents age and gender predicts students psychological wellbeing. Deasy, et al.'s (2014) result is supported Aro, et al. (2019) whose findings also revealed that differences in age and gender has an effect on the psychological distress among students with learning disabilities.

According to Aro, et al. (2019) knowledge about gender-related differences in the level of psychological problems among people with learning disabilities is controversial. For instance, in their studies Altemus, Sarvaiya and Epperson (2014) and Kessler (2003) discovered that generally, females are more susceptible in developing anxiety and depression than their male counterparts. Yet, most Nelson and Harwood (2011) argues that even though the above assertion is true studies that came to the conclusion that females experience higher rates of depression and anxiety were most mostly conducted among normal students and not those with learning disabilities. Nevertheless, Heath and Ross (2000), and Nelson and Gregg (2012) have found depressive symptoms and anxiety more prevalent in girls with learning disabilities than boys.

\section{Vi. Conclusion and Recommendations}

\section{a) Conclusion}

This study examined the extent to which social support and self-esteem predict psychological distress among students with learning disabilities at Multi Kids Inclusive Academy in Accra, Ghana. After testing the various hypothesis, results revealed that a significant negative relationship exists between self-esteem and psychological distress among students. Finally, result showed that differences in gender and age predicted psychological distress among students with learning disabilities. It is concluded that, the level of social support students with disabilities in learning receive from their teachers and classmates, and positive self-concept protect them against psychological distress (i.e. depression, anxiety and stress).

\section{b) Relevance of the study}

This study is unique because it is one of the few studies done in Ghana targeting children with learning disabilities. Even though similar studies have been done in Ghana by other researchers, only but a few has been done targeting children with learning disabilities. Hence, the fact that this study focused on the level of social support (from parents, teachers and classmates), selfconcept and psychological distress makes it one of the ground breaking study in Ghana.

This study has as well revealed the importance of social support (especially social support from teachers and classmates) in reducing psychological distress and augmenting the self-concept of children having learning disabilities. Even though social support is believed to be of great benefit students (such as enhancing their academic performance, etc.) this study has shown that social support from teachers and classmates goes further to enhance students' psychological well-being. Parents and teachers could therefore take advantage of this discovery to improve the level of social support, self-concept and psychological health of students with learning disabilities.

This study has also given some hope to families with children with learning disabilities because it has been empirically proven that students or children with learning disabilities do not have a bleak future as presumed in Ghana, and in most third world countries. And that giving them the needed social support will reduce psychological distress (stress, anxiety and depression) and enhance their psychological well-being.

\section{c) Limitation of the study}

The quantitative research method adopted in this study is one of its limitation. This is because it gave little room for respondents to give further explanation to their responses as the questionnaire was made up of Likert scale survey questions. 
Also, this study did not focus on the effect of the various types of social support (tangible, emotional, esteem and informational) on psychological distress. A consideration of the extent to which different types of social support predict psychological distress may be unearthed further result that would have enabled stakeholders (such as parents, teachers, among others) to understand and appreciate how various types of social support serves as a buffer against psychological distress.

\section{d) Recommendations}

Future studies should compare the levels social support, self-concept and psychological distress among students with learning disabilities and those without learning disabilities so as to determine whether differences will exist between the two groups. This is important because it will help to determine whether learning disability is a mediating variable between social support, self-concept and psychological distress.

Social support from teachers and classmates has been found to reduce psychological well-being among students with disabilities. Based on this result it is recommended that, parents, should step up and sustain the social support the offer to their children with learning disabilities. This is important because doing so will go a long way to enhance the psychological wellbeing of students with learning disabilities. According to Waters, et al. (2013) social support from parents has the most significant effect against psychological distress. This could be done by spending more quality time with children especially those with learning disabilities. When together, parent could seek to know what their children have been up to, the challenges they encounter in on a daily basis, and engage them in solves their problems.

It is also recommended to other stakeholders such as Teachers, Child Psychologists, Educational Psychologists, among others to consider social support as part of their therapies offered to student and children with learning disabilities, to enable them cope with psychological distress and behavior problems. Parents, guardians and other caregivers of students with learning disabilities could also be educated to understand the importance of social support to the enhancement of psychological wellbeing of children with learning disabilities.

Even though getting students with learning disabilities to use for research is difficult, future studies are encouraged to use a larger sample size than the one used in this present study. This will enhance the extent to which findings is generalized as reflection of the general population of student with learning disabilities.

Finally, the mixed method research approach will have been more desirable than the quantitative research method used. Mixed method has to do with the systematic integration, or mixing, of both qualitative and quantitative and data (and analysis) within a single research. It is, therefore, recommended to researchers who have interest in conducting a similar study to consider the mixed method research approach. Doing so will allow respondents to elucidate their responses to enhance readers understanding.

\section{References Références Referencias}

1. Alesi, M., Rappo, G. \& Pepi, A. (2014). Depression, Anxiety at School and Self-Esteem in Children with Learning Disabilities. Journal of Psychological Abnormalities in Children, 3 (3) 1-8. Doi:10.4172/ 2329-9525.1000125.

2. Altemus, M., Sarvaiya, N., \& Epperson, C. (2014). Sex differences in anxiety and depression clinical perspectives. Frontiers in Neuroendocrinology, 35, 320-330

3. Aro, T., Eklund, K., Eloranta, A-K., Närhi, V., Korhonen, E. \& Ahonen T. (2019). Associations Between Childhood Learning Disabilities and AdultAge Mental Health Problems, Lack of Education, and Unemployment. Journal of Learning Disabilities, 52(1) 71-83. Doi:10.1177/0 022219418775118

4. Attah, D. (2010). Learning disabilities and academic achievement amongst school children in Accra. Retrieved on 10th May, 2021 from http://197.255. 68.203/handle/123456789/7337

5. Bane, G., Deely, M, Donohoe, B., Dooher \& M., Flaherty, J (2012). Relationships of people with learning disabilities in Ireland. British Journal of Learning Disabilities, 40 (2) 109-122.

6. Barrett, A. (2012). Childhood maltreatment and structural neuroanatomy as risk factors for adolescent onset depression. Retrieved on 10th May, 2021 from https://minerva-access.unimelb.e du.au/bitstream/handle/11343/38429/303585_Anna \%20Barrett\%2065747\%20PhD\%20Amendments.pdf ?isAllowed $=y \&$ sequence $=1$

7. Barth J, Schneider S. \& von Kanel R. (2010). Lack of social support in the etiology and prognosis of coronary heart disease: A systematic review and meta-analysis. Psychosomatic Medicine, 72, 229238. Doi:10.1097/PSY.0b013e3181d01611.

8. Baumeister, R. F. (1999). The nature and structure of the self: An overview. The self in social psychology, 4(3) 1-20.

9. Bellmore, A. D. \& Cillessen, A. R. N. (2006). Reciprocal influences of victimization, perceived social preferences, and self-concept in adolescence. Self and Identity, 5, 209-229.

10. Carlton, B. S., Goebert, D. A., Miyamoto, R. H., Andrade, N. N., Hishinuma, E. S. \& Makini, G. K. J. (2006). Resilience, family adversity and well-being among Hawaiian and non-Hawaiian adolescents. International Journal of Social Psychiatry, 52(4), 291-308. 
11. Cataudella S, Carta S, Mascia ML, Masala C, Petretto D. R. \& Penna, M. P. (2021). Psychological Aspects of Students With Learning Disabilities in E-Environments: A Mini Review and Future Research Directions. Frontiers in Psychology, 11, 611818. Doi:10.3389/fpsyg.2020.611818

12. Cavioni, V., Grazzani, I. \& Ornaghi, V. (2017). Social and emotional learning for children with Learning Disability: Implications for inclusion. Discussion Paper, 9 (2) 100-109.

13. Cherry, K. (2017). What exactly is self-esteem? Signs of healthy and low self-esteem. Retrieved on 2nd January, 2021 from https://www.verywellmind. com

14. Coster, W., Law, M., Bedell, G., Liljenquist, K., Kao, Y.C., Khentani, M., \& Teplicky, R. (2012). School participation, supports and barriers of students with and without disabilities. Child Care, Health and Development, 39, 535-543. Doi:10.1111/cch.12046

15. Creswell, J. W. (2014). Research Design: Qualitative, Quantitative and Mixed Methods Approaches (4th Ed.). Thousand Oaks, CA: Sage

16. Cukor, D. \& Kimmel, P. L. (2017). Psychosocial Issues in Dialysis. Patients Handbook of Dialysis Therapy, (5).

17. Dagnan, D. \& Sandhu, S. (1999). Social comparison, self-esteem and depression in people with intellectual disability. Journal of Intellectual Disability Research, 43(5), 372-379

18. Deasy, C., Coughlan, B., Pironom, J., Jourdan, D. \& Mannix-McNamara, P. (2014) Psychological Distress and Coping amongst Higher Education Students: A Mixed Method Enquiry. PLOS ONE 9(12): e115193. Retrieved on $2^{\text {nd }}$ January, 2021 from https://doi.org/10.1371/journal.pone.011 5193

19. DeGarmo, D., Patras, J. \& Eap, S. (2008). Social Support for Divorced Fathers' Parenting: Testing a Stress-Buffering Model. Family Relations, 57, 35-48. Doi:10.1111/j.1741-3729.2007.00481.x.

20. Del Valle, F. J., Bravo, A., \& Lopez, M. (2010). Parents and peers as providers of support in adolescents' social network: a developmental perspective. Doi.org/10.1002/jcop.20348

21. Ehmke, R. (2021). Supporting the Emotional Needs of Kids with Learning Disabilities. Retrieved on 10th May, 2021 from https://childmind.org/article/ supporting-the-emotional-needs-of-kids-withdisabilities/

22. Fauziah, M. \& Muslihati, D, M. H. (2018). Selfesteem, Social Support, Personality and Psychological Well Being of Junior High School Student. Jurnal Pendidikan Humaniora, 6 (1) 17-23

23. Flisher A. J., Malhotra S., Nikapota A. \& Patel V. (2008). Promoting child and adolescent mental health in low and middle income countries. Journal of Child Psychology and Psychiatry. 49(3) 313-334.
24. Fiorillo, C. \& Sabatini, F. (2011). Quality and quantity: The role of social interactions in selfreported individual health. Social Science \& Medicine, 73, 1644-1652. Doi:10.1016/j.socscim ed.2011.09.007

25. Gans, M., Kennym, M \& Ghany, L (2003). Comparing the Self-Concept of Students with and without learning disabilities. Journal of learning disabilities, 36, 287-95. Doi:10.1177/0022219403 03600307.

26. Gerich, J. (2013). Effects of Social Networks on Health from a Stress Theoretical Perspective. Social Indicators Research, 118 (1) 349-364. DOI:10. 1007/s11205-013-0423-7.

27. Hapke, L. (2015). Social Support Networks Among Children with Intellectual and Developmental Disabilities. Honors Theses and Capstones, 250. Retrieved on 10th May 2021 from https://schola rs.unh.edu/honors/250

28. Harter, S. (1985). Manual of the Self-Perception profile for Children. Revision of perceived competence scale for children. Denver: University of Denver

29. Heath, N., \& Ross, S. (2000). Prevalence and expression of depressive symptomatology in students with and without learning disabilities. Learning Disability Quarterly, 23, 24-36

30. Heiman, T. (2006). Social support networks, stress, sense of coherence and academic success of university students with learning disabilities. Social Psychology and Education, 9, 461-478. Retrieved on 10th May 2021 https://doi.org/10.1007/s11218-0069007-6

31. Hobfoll, S. E. (2001). The influence of culture, community, and the nested-self in the stress process: Advancing Conservation of Resources theory. Applied Psychology: An International Review, 50(3) 337-370.

32. Jeena, S. P. \& Aswathi, R. K. (2004). Family relationship and emotional stability of adolescents with learning disabilities. Journal of Personality and Clinical studies, 20 (2) 47- 53.

33. Jobson-Mitchual, C. (2018). Social Support, SelfConcept and Psychological Distress amongst Students with Learning Disabilities in Accra. Unpublished MPhil Guidance and Counseling Degree Submitted University of Ghana

34. Kavale, K. A., \& Forness, S. R. (1996). Social skills deficits and learning disabilities: A meta analysis. Journal of Learning Disabilities, 29, 226-237.

35. Kavale, K. A., \& Forness, S. R. (2003). Learning disabilities as a discipline. In H. L. Swanson, K. R. Harris, \& S. Graham (Eds.), Handbook of learning disabilities (pp. 76-93). New York: Guilford Press.

36. Khan, A. (2016). Influence of Academic Stress on Students' Self-Concept, Adjustment and Achievement Motivation. Thesis submitted Aligarh 
Muslim University, India for the award of the Degree of Doctor of Philosophy in Psychology

37. Kloomok, S., \& Cosden, M. (1994). Self-Concept in Children with Learning Disabilities: The Relationship between Global Self-Concept, Academic "Discounting," Nonacademic SelfConcept, and Perceived Social Support. Learning Disability Quarterly, 17(2), 140-153.

38. Lagana, M. T. (2004). Protective factors for inner-city adolescents at risk of school dropout: Family factors and social support. Children \& Schools, 26 (4), 211-220.

39. Lahane S, Shah H, Nagarale V, Kamath R. (2013). Comparison of self-esteem and maternal attitude between children with learning disability and unaffected siblings. Indian Journal Pediatric, 80 (9) 745-749. Doi:10.1007/s12098-012-0915-5.

40. Leminen, A. (2002). Self-concept of children in special and regular education. Retrieved on 15th May 2021 from https://jyx.jyu.fi/bitstream/handle/ 123456789/7866/G0000081.pdf?seq

41. Lindeblad, E., Nilsson, S. Gustafson, S. \& Svensson, I. (2019). Self-concepts and psychological health in children and adolescents with reading difficulties and the impact of assistive technology to compensate and facilitate reading ability. Cogent Psychology, 6 (1), 1647601. DOI:10. 1080/2 3311908.2019.1647601

42. Lovibond, S. H. \& Lovibond, P. F. (1995). Manual for the Depression Anxiety \& Stress Scales. (2nd Ed.) Sydney: Psychology Foundation.

43. Malecki, C. \& Demaray, M (2002). Measuring perceived social support: Development of the child and adolescent social support scale (CASSS), 39(1) 1-18. DOI: 10.1002/pits.10004.

44. Martínez, S. R., Aricak, T. O., Graves, N. M., PetersMyszak, J. \& Nellis, L. (2011). Changes in perceived social support and socioemotional adjustment across the elementary to junior high school transition. Journal Youth Adolescence, 40(5) 519530. Doi: 10.1007/s10964-010-9572-z.

45. McKenzie, K., Murray, G. \& Derries, P. (2020). Factors influencing the self-esteem of children with a severe or profound learning disability: a pilot study. Learning Disability Practice, 23 (3) 25-30. Doi:10.7748/ldp.2020.e2077

46. Nelson, J., \& Harwood, H. (2011). A meta-analysis of parent and teacher reports of depression among students with learning disabilities: Evidence for the importance of multi-informant assessment. Psychology in the Schools, 48, 371-384.

47. Nunnally, J. C. (1978). Psychometric Theory (2nd Ed.). New York: McGraw-Hill.

48. Ozbay, F., Johnson, D. C., Dimoulas, E., Morgan, C. A., Charney, D., \& Southwick, S. (2007). Social Support and Resilience to Stress: From
Neurobiology to Clinical Practice. Psychiatry (Edgmont), 4(5), 35-40.

49. Papanastasiou, F. (2017) The Psychological Implication of Learning Disabilities. Acta Psychopathol, 4 (1). Retrieved on 2nd January 2021 from https://psychopathology.imedpub.com/thepsychological-implication-of-learning-disabilities. php?aid $=21693$

50. Pavri, S. \& Monda-Amaya, L. (2001). Social Support in Inclusive Schools: Student and Teacher Perspectives. Exceptional Children, 67(3), 391-411.

51. Puspalata. (2008). Relationship Between Academic Competence and Social Anxiety of Learning Disabled Children. Journal for Psychology. Coimbatore.

52. Pestana, C. (2015). Exploring the self-concept of adults with mild learning disabilities. British Journal of Learning Disabilities, 43, 16-23. Doi:10.1111/bld. 12081

53. Pinquart, M., \& Duberstein, P. (2010). Depression and Cancer mortality: A meta-analysis. Psychological Medicine, 40(11), 1797-1810

54. Ramaa, S. (2000). Two decades of research on learning disabilities in India. Dyslexia, 6 (4) 268-283

55. Rosario, M., Salzinger, S., Feldman, R. S. \& NgMak, D. S. (2008). Intervening processes between youths' exposure to community violence and internalizing symptoms over time: The roles of social support and coping. American Journal of Community Psychology, 41, 43-62.

56. Rothman, H. R. \& Cosden, M. (1995). The Relationship between Self-Perception of a Learning Disability and Achievement, Self-Concept and Social Support. Learning Disability Quarterly, 18(3), 203-212.

57. Sahoo, K. M., Biswas, H. \& Padhy, K. S. (2015). Psychological Co-morbidity in Children with Specific Learning Disorders. Journal of Family Medical Primary Care, 4(1) 21-25. DOI:10.4103/2249-4863. 152243.

58. Scott, E. (2020). The Different Types of Social Support. Retrieved on 15th May 2021 from https:// www.verywellmind.com/types-of-social-support-314 4960

59. Shukla, P. \& Agrawal, G. (2015). Awareness of Learning Disabilities among Teachers of Primary Schools. Online Journal of Multidisciplinary Research, 1 (1) 33-38.

60. Sternke, J. C. (2010). Self-concept and self-esteem in adolescent with learning disabilities. Retrieved on 4th May 2021 from http://www2.uwstout.edu/ content/lib/thesis/2010/2010sternk ej.pdf

61. Suldo, S. M., Mihalas, S., Powell, H., \& French, R. (2008). Ecological predictors of substance use in middle school students. School Psychology Quarterly, 23(3) 373-388. 
62. Svetaz, M. V., Ireland, M., \& Blum, R. (2000). Adolescents with learning disabilities: Risk and protective factors associated with emotional wellbeing: Findings from the National Longitudinal Study of Adolescent Health. Journal of Adolescent Health, 27(5), 340-348

63. Tabachnick, B. G., \& Fidell, L. S. (2013). Using Multivariate Statistics (6th Ed.). New Jersey: Pearson Education Inc.

64. Tam, H. \& Hawkins, R. (2012). Self-concept and depression levels of students with dyslexia in Singapore. 6th Annual International Conference on Psychology, 28-31.

65. Tiga, S. M. \& Vashishtha, K. C. (2010). Social Competence as a determinant of Self-concept and Social Anxiety of Learning Disabled and Non learning Disabled Adolescents. (4), Dayalbagh Educational Institute. Dayalbagh. Agra.

66. Walsh, E. K. (2018). Self-Concept in Middle Year Students with Learning Disabilities. Retrieved on 10th May 2021 from https://open.library.ubc.ca/ collections/ubctheses/24/items/1.0372955

67. Waters, S., Lester, L., \& Cross, D. (2013). How does support from peers compare with support from adults as students' transition to secondary school? Journal of Adolescent Health, 54, 543-549.

68. Wendelborg, C. \& Kvello, O. (2010). Perceived Social Acceptance and Peer Intimacy Among Children with Disabilities in Regular Schools in Norway. Journal of Applied Research in Intellectual Disabilities, 23(2) 143 - 153

69. Whitley, J. (2008). Following Paths to Self-Concept for Students with Learning Disabilities. Retrieved on 10th May 2021 from https://www.waterstones.com/ book/following-paths-to-self-concept-for-studentswith-learning-disabilities/jessica-whitley//97836390 61390

70. Wiesner-Groff, A. (2021). Building Self-Esteem in Children with Learning Disabilities. Retrieved on 10th May 2021 from https://study.com/academy/lesson/ building-self-esteem-in-children-with-learningdisabilities.html

71. Yekple, Y. E. \& Avoke, M. (2006). Improving inclusive education at the basic school level in Ghana. African Journal of Special Educational Needs, 5 (2) 239-249.

72. Zhang, B., Yan, X., Zhao, F. \& Yuan, F. (2014). The relationship between perceived stress and adolescent depression: The roles of social support and gender. Social Indicators Research, 1-18. Doi: 10.1007/s11205-014-0739-y

73. Zeleke, S. (2004) Self-concepts of students with learning disabilities and their normally achieving peers: a review. European Journal of Special Needs Education, 19 (2), 145 170. DOI:10.1080/08856250 410001678469
74. Zigmond, N. (1993). Learning disabilities from an educational perspective. In G. R. Lyon, D. B. Gray, J. R. Kavanagh, \& N. A. Krasnegor (Eds.), Better understanding learning disabilities: New views from research and their implications for education and public policies (pp.251-272). Baltimore: Brookes. 